\title{
OAP Regimen
}

National Cancer Institute

\section{Source}

National Cancer Institute. OAP Regimen. NCI Thesaurus. Code C9624.

A chemotherapy regimen consisting of vincristine, cytarabine, and prednisone that may be used in the treatment of acute myeloid leukemia (AML). 